\title{
High rate and selective etching of GaN, AIGaN, and AIN using an inductively coupled plasma
}

\author{
S. A. Smith, ${ }^{\text {a) }}$ C. A. Wolden, M. D. Bremser, A. D. Hanser, and R. F. Davis \\ Department of Materials Science and Engineering, North Carolina State University, Raleigh, \\ North Carolina 27695-7919 \\ W. V. Lampert \\ Materials Directorate, Air Force Research Laboratory, Wright Patterson Air Force Base, Ohio 45433-7750
}

(Received 23 July 1997; accepted for publication 22 October 1997)

The etching behavior of gallium nitride $(\mathrm{GaN})$, aluminum gallium nitride $\left(\mathrm{Al}_{x} \mathrm{Ga}_{1-x} \mathrm{~N}\right)$, and aluminum nitride (AlN) has been systematically examined in an inductively coupled plasma (ICP) using $\mathrm{Cl}_{2}$ and $\mathrm{Ar}$ as the reagents. Etch rates were strongly influenced by ICP power and dc bias, while relatively insensitive to pressure, flow rate, and gas composition. Maximum etch rates of 9800 $\AA /$ min for $\mathrm{GaN}, 9060 \AA / \mathrm{min}$ for $\mathrm{Al}_{0.28} \mathrm{Ga}_{0.72} \mathrm{~N}$, and $7490 \AA / \mathrm{min}$ for AlN were attained. The etch profiles were highly anisotropic over the range of conditions studied. The dc bias had to exceed certain voltages before significant etch rates were obtained. These values were $<-20 \mathrm{~V}$ for GaN, $-40 \mathrm{~V}$ for $\mathrm{Al}_{0.28} \mathrm{Ga}_{0.72} \mathrm{~N}$, and $>-50 \mathrm{~V}$ for AlN. As such, increasing selectivity for GaN over $\mathrm{Al}_{0.28} \mathrm{Ga}_{0.72} \mathrm{~N}$ and AlN was achieved at dc biases below $-40 \mathrm{~V}$. At $-20 \mathrm{~V}$, the $\mathrm{GaN}$ etch rates were 38 times greater than $\mathrm{AlN}$ and a factor of 10 greater than $\mathrm{Al}_{0.28} \mathrm{Ga}_{0.72} \mathrm{~N}$. These results demonstrate the importance of ion bombardment in the etching of these materials. (C) 1997 American Institute of Physics. [S0003-6951(97)03651-6]

The realized and future potential of $\mathrm{GaN}, \mathrm{AlN}$, and $\mathrm{Al}_{x} \mathrm{Ga}_{1-x} \mathrm{~N}$ for short wavelength light emitters and detectors, and high-temperature and high-power electronics is considerable. ${ }^{1,2}$ Etching anisotropic features is a crucial step in the fabrication of many of these devices. Wet chemical etching of $\mathrm{GaN}$ has to date produced only slow etch rates and isotropic etch profiles, ${ }^{3}$ both of which are undesirable for commercial applications. Dry etching is an attractive alternative from which one can achieve controlled degrees of anisotropy, high etch rates, material selectivity, low damage, and the ability to control an etch stop.

The four primary dry techniques that have been employed to etch $\mathrm{GaN}$ are reactive ion etching (RIE), electron cyclotron resonance etching (ECR), magnetron reactive ion etching (MIE), and inductively coupled plasma etching (ICP). ${ }^{4-6}$ The slowest etch rates and the lowest degree of anisotropy were determined for RIE. This has been attributed to the low plasma densities and the higher operating pressures inherent in this technique. The other three process routes are high density, low pressure alternatives to the parallel plate reactor. To date, the use of ECR has produced the fastest $\mathrm{GaN}$ etch rates of $13000 \AA / \mathrm{min}$ with an ICl chemistry. ${ }^{7}$ Rates of $6875 \AA$ Amin were attained with an ICP system and $\mathrm{Cl}_{2} / \mathrm{H}_{2} / \mathrm{Ar}$ mixture. ${ }^{8}$

Chlorine-based gases such as $\mathrm{BCl}_{3}, \mathrm{SiCl}_{4}$, and $\mathrm{Cl}_{2}$ are the primary reagents that have been employed to etch the III-Nitrides. Vartuli et al. have reported a dry technique that etches GaN selectivity with respect to AIN and $\mathrm{Al}_{x} \mathrm{Ga}_{1-x} \mathrm{~N}^{9}{ }^{9,10}$ Selectivities of 10 between $\mathrm{GaN}$ and $\mathrm{AlN}$, and 4 between $\mathrm{GaN}$ and $\mathrm{Al}_{0.31} \mathrm{Ga}_{0.69} \mathrm{~N}$ were reported. In this letter we report the results of a systematic study of ICP etching of III-Nitrides using a $\mathrm{Cl}_{2} / \mathrm{Ar}$ chemistry. Selective etch-

${ }^{a)}$ Permanent address: Materials Directorate, Air Force Research Laboratory, Wright Patterson Air Force Base, OH 45433-7750. ing of GaN relative to both $\mathrm{AIN}$ and $\mathrm{Al}_{0.28} \mathrm{Ga}_{0.72} \mathrm{~N}$ was achieved by controlling the dc bias. The dependence of the etch rate on both ICP power and dc bias are also reported for the three materials. Lastly, the anisotropic nature of the etch profiles is demonstrated.

The ICP system was a custom built, $41 \mathrm{~cm}$ diameter by $58 \mathrm{~cm}$ tall, load-locked stainless-steel chamber. The rf power was coupled through a $32.4 \mathrm{~cm}$ diameter quartz window at the top of the chamber. The inductive source was a planar, 4 turn, $23 \mathrm{~cm}$ diameter copper coil which was connected to a rf power products $2 \mathrm{~kW}$ rf generator operating at $13.56 \mathrm{MHz}$ via an autotuning matching network. Gas was fed into the chamber through a stainless-steel shower ring positioned level with the bottom of the quartz window. A water-cooled wafer chuck was mounted on a motor driven vertical translation stage which had $30.5 \mathrm{~cm}$ of travel. This allowed samples to be transferred between the load-lock chamber and the processing zone. A second $500 \mathrm{~W}$ rf source was connected to the wafer chuck to apply a controllable dc bias to the substrate. The substrate cooling water was maintained at $16{ }^{\circ} \mathrm{C}$ to prevent the baking of photoresist during etching. The chamber was evacuated by an Alcatel $900 \ell / \mathrm{s}$ turbomolecular pump which attained a base pressure of $10^{-7}$ Torr.

A magnetic bucket containing $240 \mathrm{Nd}-\mathrm{Fe}-\mathrm{B}$ magnets was mounted on the outside perimeter of the chamber to increase the plasma density by confining the electrons to a central volume within the chamber. This reduced electron losses due to collisions with the chamber walls. The ions were also confined due to electrostatic coupling with the electrons. The former were not directly affected by the magnetic field. ${ }^{11}$

The GaN, AlN, and $\mathrm{Al}_{0.28} \mathrm{Ga}_{0.72} \mathrm{~N}$ samples used for this study were epitaxially grown on $6 \mathrm{H}-\mathrm{SiC}-(0001)$ substrates via metalorganic vapor phase epitaxy (MOVPE) using trimethylaluminum (TMA) and triethylgallium (TEG) as the Al 
TABLE I. The experimental parameters examined, their ranges, and the base conditions employed in this study.

\begin{tabular}{lll}
\hline \hline Parameter & \multicolumn{1}{c}{ Range } & Base Cond. \\
\hline ICP power & $100-1100 \mathrm{~W}$ & $500 \mathrm{~W}$ \\
DC bias & $20-450(-\mathrm{V})$ & $-150 \mathrm{~V}$ \\
Pressure & $1-9 \mathrm{mTorr}$ & $5 \mathrm{mTorr}$ \\
Total flow rate & $10-30 \mathrm{sccm}$ & $25 \mathrm{sccm}$ \\
$\mathrm{Cl}_{2}$ Percentage & $50-100 \%$ & $80 \%$ \\
$\mathrm{Ar}$ percentage & $0-50 \%$ & $20 \%$ \\
\hline \hline
\end{tabular}

and $\mathrm{Ga}$ sources, respectively, and $\mathrm{NH}_{3}$ as the nitrogen source. $^{12,13} \mathrm{An} \approx 100 \mathrm{~nm}$ AlN buffer layer was deposited on the $\mathrm{SiC}$ substrates prior to the growth of the $\mathrm{GaN}$ and the $\mathrm{Al}_{0.28} \mathrm{Ga}_{0.72} \mathrm{~N}$. Preparation of the samples for etching employed the sequence of applying a $\mathrm{Ni}$ coating, patterning with photoresist, and dipping into $\mathrm{HNO}_{3}$ to etch away the $\mathrm{Ni}$ and into acetone to remove the photoresist. Just prior to entry into the etching system, the samples were dipped into $10 \%$ $\mathrm{HF}$ acid for $10 \mathrm{~min}$ to remove oxygen and carbon contaminants. Samples were attached to a $7.6 \mathrm{~cm}$ diameter anodized aluminum transport plate using vacuum grease which was mounted onto the wafer chuck. After entry into the system a base pressure of $\leqslant 5 \times 10^{-7}$ Torr was attained before the etching experiments were initiated.

The etch rates were determined by the step heights measured using a Dektak II profilometer. Anisotropy was determined by scanning electron microscopy (SEM). Other effects such as electrical damage, physical damage, and chemical contamination are currently being investigated.

The etching parameters studied and the ranges examined are summarized in Table I. The dc bias was varied instead of bias power since the former more directly determines the energy of the ions which strike the surface. The three samples were etched simultaneously to ensure accurate comparisons. It was determined that the gas phase concentration and total flow rate within the ranges shown in Table I had no significant impact on the etch rates $(<20 \%)$. The etch rate was slightly more sensitive to pressure, varying $44 \%$ over the range investigated. A more extensive study of all parameters using optical emission spectrometry (OES) and mass spectrometry will be reported at a later date.

Figure 1 shows that the etch rates for the three materials as a function of ICP power for the three materials behaved similarly. The etch rates increased rapidly from 100 to 500 $\mathrm{W}$. Above $500 \mathrm{~W}$ the rate of increase was slightly attenuated, although no maximum was reached. Between 900 and 1100 $\mathrm{W}$, the etch rates of the $\mathrm{Al}_{0.28} \mathrm{Ga}_{0.72} \mathrm{~N}$ closely matched those of the GaN. The observed increase in the etch rates with ICP power was likely due to increases in both the reactive chlorine concentration and the ion density. Additional diagnostics are necessary to distinguish between these two effects. The maximum etch rates achieved at an ICP power of 1100 W were $9140 \AA / m i n$ for the $\mathrm{GaN}, 9060 \AA / \mathrm{min}$ for the $\mathrm{Al}_{0.28} \mathrm{Ga}_{0.72} \mathrm{~N}$, and $7490 \AA / \mathrm{min}$ for the AlN.

The etch profiles were highly anisotropic over all conditions examined. Figure 2 shows a typical profile obtained under the base conditions (see Table I) using nickel as the etch mask. The vertical striations were transferred from imperfections in the mask edge. The etched surface was smooth

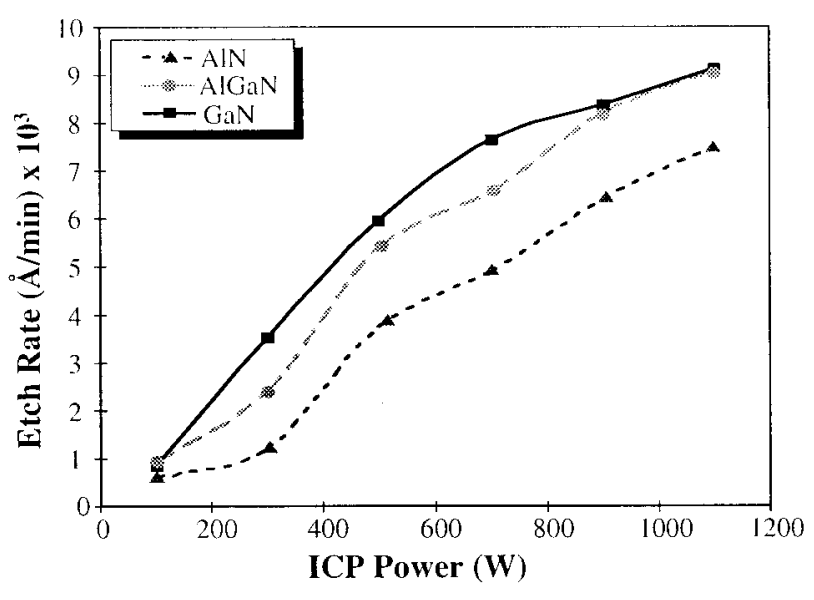

FIG. 1. The etch rates of $\mathrm{GaN}, \mathrm{Al}_{0.28} \mathrm{Ga}_{0.72} \mathrm{~N}$, and $\mathrm{AlN}$ as a function of ICP power.

and appeared to be free of physical damage such as pitting.

The dc bias had a very pronounced effect on the etch rates for all three materials, as shown in Fig. 3. Again, the behavior was qualitatively similar for the three materials. Firstly, each material had a threshold voltage below which the etch rates were very low. These voltages were: $<-20 \mathrm{~V}$ for $\mathrm{GaN}, \sim-40 \mathrm{~V}$ for $\mathrm{Al}_{0.28} \mathrm{Ga}_{0.72} \mathrm{~N}$, and between -50 and $-150 \mathrm{~V}$ for AlN. Above the threshold value the rates increased dramatically to $-250 \mathrm{~V}$ at which point a plateau occurred for the three materials. Between -350 and $-450 \mathrm{~V}$ the rates increased again, suggesting that an additional etching mechanism may be operative at these high biases. The maximum rates achieved at a dc bias of $-450 \mathrm{~V}$ were $9800 \AA / \mathrm{min}$ for $\mathrm{GaN}, 8670 \AA / \mathrm{min}$ for $\mathrm{Al}_{0.28} \mathrm{Ga}_{0.72} \mathrm{~N}$, and $6700 \AA / \mathrm{min}$ for $\mathrm{AlN}$.

The etch selectivity of $\mathrm{GaN}$ relative to $\mathrm{AlN}$ and $\mathrm{Al}_{x} \mathrm{Ga}_{1-x} \mathrm{~N}$ is of significant interest for the fabrication of $\mathrm{Al}_{x} \mathrm{Ga}_{1-x} \mathrm{~N}$ based heterostructure devices. One example is the etch penetration through a $\mathrm{GaN}$ capping layer to the $\mathrm{Al}_{x} \mathrm{Ga}_{1-x} \mathrm{~N}$ recessed gate in a high electron mobility transistor. Etching of the latter material should be minimal. Selective etching was achieved at low dc biases. The data from Fig. 3 were converted into selectivity and plotted in Fig. 4

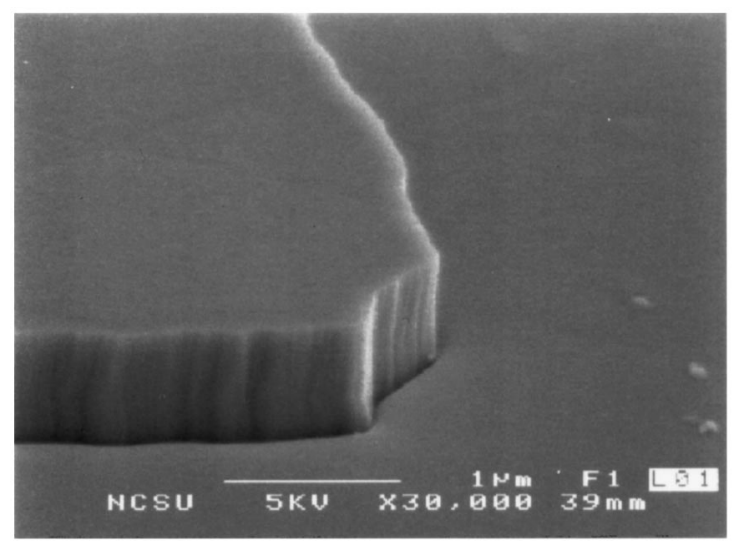

FIG. 2. Typical etch profile using $\mathrm{Ni}$ as the etch mask under base conditions. Vertical striations were transferred from imperfections in the mask edge. 


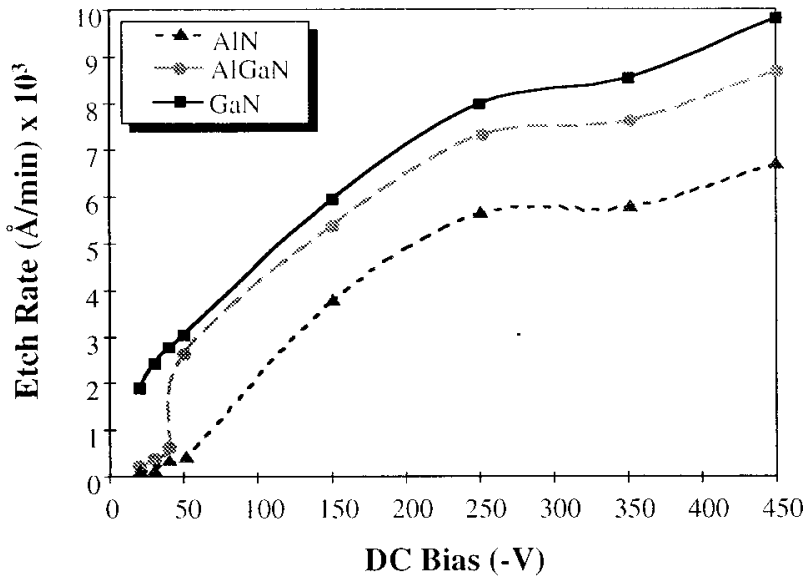

FIG. 3. The etch rates of $\mathrm{GaN}, \mathrm{Al}_{0.28} \mathrm{Ga}_{0.72} \mathrm{~N}$, and $\mathrm{AlN}$ as a function of $\mathrm{dc}$ bias.

for $\mathrm{GaN}$ relative to $\mathrm{Al}_{0.28} \mathrm{Ga}_{0.72} \mathrm{~N}$ and $\mathrm{AlN}$ over the range of $-(20-50 \mathrm{~V})$. The selectivity is the ratio of the etch rate of $\mathrm{GaN}$ to the $\mathrm{AlN}$ or $\mathrm{Al}_{x} \mathrm{Ga}_{1-x} \mathrm{~N}$. At $-50 \mathrm{~V}$, the selectivity between $\mathrm{GaN}$ and $\mathrm{AlN}$ was 8.5; whereas, it was only 1.2 between the $\mathrm{GaN}$ and $\mathrm{Al}_{0.28} \mathrm{Ga}_{0.72} \mathrm{~N}$. The greatest selectivities for $\mathrm{GaN}$ were found at a bias of $-20 \mathrm{~V}$, a factor of 38 over AlN and approximately 10 over $\mathrm{Al}_{0.28} \mathrm{Ga}_{0.72} \mathrm{~N}$. These differences in etch rates are consistent with the different bond energies between $\mathrm{Ga}-\mathrm{N}$ and $\mathrm{Al}-\mathrm{N}$ of 8.92 and 11.52 eV/atom, respectfully. ${ }^{14} \mathrm{~A}$ second factor is the lower volatility of $\mathrm{AlCl}_{x}$ relative to $\mathrm{GaCl}_{x}$. Since lower dc biases were used to attain the selective etching, there is a tradeoff between the selectivity and the total etch rate.

The strong dependence of the etch rate on dc bias indicates that ion bombardment plays a significant role in the

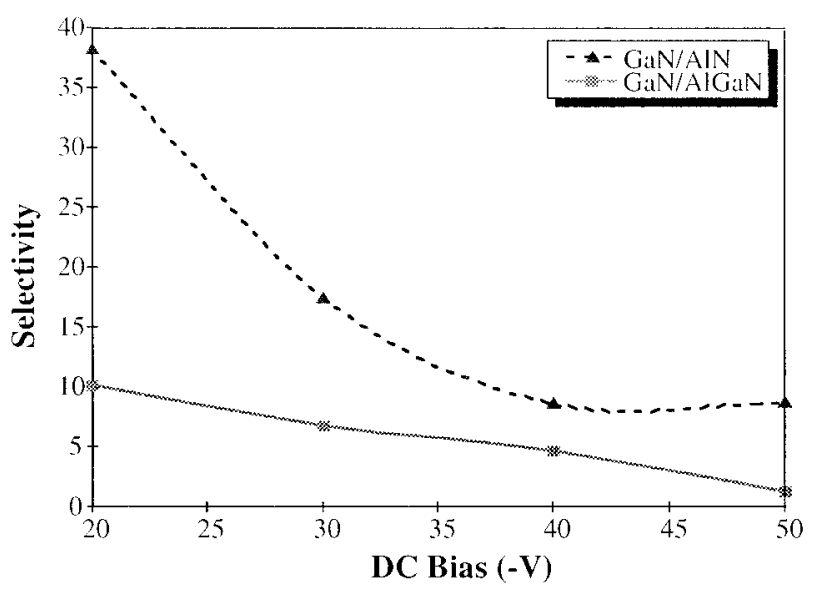

FIG. 4. The selectivity of GaN relative to $\mathrm{Al}_{0.28} \mathrm{Ga}_{0.72} \mathrm{~N}$ and $\mathrm{AlN}$ as a function of dc bias. Values of selectivity were obtained from the GaN/AIN and $\mathrm{Al}_{0.28} \mathrm{Ga}_{0.72} \mathrm{~N}$ etch rate ratios using the data for the individual etch rates shown in Fig. 3. etching of these materials. Ion bombardment can enhance etching via damaging the surface to make it more reactive, stimulating desorption of the etch products, and direct physical sputtering. The existence of a threshold bias indicates that breaking $\mathrm{Ga}-\mathrm{N}$ or $\mathrm{Al}-\mathrm{N}$ bonds by ion bombardment may be the rate-limiting step. It is presumed that ion damage increases the reactivity of these ordinarily inert materials. The ion-induced damage may be necessary to form the volatile $\mathrm{GaCl}_{x} / \mathrm{AlCl}_{x}$ etch products.

In summary, dry etching of GaN, $\mathrm{AlN}$, and $\mathrm{Al}_{0.28} \mathrm{Ga}_{0.72} \mathrm{~N}$ have been investigated in an ICP system using $\mathrm{Cl}_{2}$ and $\mathrm{Ar}$ as the process gases. The rates for all three materials depended strongly on both the ICP power and the dc bias. Maximum etch rates of $9800 \AA / \mathrm{min}$ for the $\mathrm{GaN}, 9060 \AA / \mathrm{min}$ for the $\mathrm{Al}_{0.28} \mathrm{Ga}_{0.72} \mathrm{~N}$, and $7490 \AA / \mathrm{min}$ for the $\mathrm{AlN}$ were achieved which are the highest reported to date for this chemistry. Threshold biases of $>-50$ and $-40 \mathrm{~V}$ were required to induce significant etching for $\mathrm{AlN}$ and $\mathrm{Al}_{0.28} \mathrm{Ga}_{0.72} \mathrm{~N}$. No threshold was found for $\mathrm{GaN}$ down to $-20 \mathrm{~V}$. As a result, selectivities of 38 between GaN and AIN and 10 between $\mathrm{GaN}$ and $\mathrm{Al}_{0.28} \mathrm{Ga}_{0.72} \mathrm{~N}$ were obtained at a dc bias of $-20 \mathrm{~V}$. This is of potential interest for the fabrication of $\mathrm{Al}_{x} \mathrm{Ga}_{1-x} \mathrm{~N}$ based heterostructure devices. Research is ongoing to quantify the effects of plasma induced damage and to better understand the underlying mechanisms.

This work was supported by the Office of Naval Research under Contract No. N00014-96-1-0765. Colin A. Wolden acknowledges support as an NRC/ARO postdoctoral fellow. Scott A. Smith wishes to acknowledge R. Claude Woods for assistance in the design of the etching system and to the U.S. Air Force PALACE Knight program.

${ }^{1}$ R. F. Davis, Proc. IEEE 79, 702 (1991).

${ }^{2}$ H. Morkoç, G. B. Gao, M. E. Lin, B. Suerdlov, and M. Burns, J. Appl. Phys. 76, 1363 (1994).

${ }^{3}$ S. J. Pearton, C. R. Abernathy, F. Ren, J. R. Lothian, P. W. Wisk, and A. Katz, J. Vac. Sci. Technol. A 11, 1772 (1993).

${ }^{4}$ R. J. Shul, S. P. Kilcoyne, M. Hagerott Crawford, J. E. Parmeter, C. B. Vartuli, C. R. Abernathy, and S. J. Pearton, Appl. Phys. Lett. 66, 1761 (1995).

${ }^{5}$ M. E. Lin, Z. F. Fan, Z. Ma, L. H. Allen, and H. Morkoç, Appl. Phys. Lett. 64, 887 (1994).

${ }^{6}$ G. F. McLane, T. Monahan, D. W. Eckart, S. J. Pearton, and C. R. Abernathy, J. Vac. Sci. Technol. A 14, 1046 (1996).

${ }^{7}$ C. B. Vartuli, S. J. Pearton, J. W. Lee, J. Hong, T. D. Mackenzie, C. R. Abernathy, and R. J. Shul, Appl. Phys. Lett. 69, 1426 (1996).

${ }^{8}$ R. J. Shul, G. B. McClellan, S. A. Casalnuovo, D. J. Rieger, S. J. Pearton, C. Constatine, C. Barratt, R. F. Karlicek, Jr., C. Tran, and M. Schurman, Appl. Phys. Lett. 69, 1119 (1996).

${ }^{9}$ C. B. Vartuli, S. J. Pearton, J. W. Lee, A. Y. Polyakov, M. Shin, D. W. Greve, M. Skronowski, and R. J. Shul, Electrochem. Soc. Interface 144, 2146 (1997).

${ }^{10}$ C. B. Vartuli, S. J. Pearton, J. D. Mackenzie, C. R. Abernathy, and R. J. Shul, Electrochem. Soc. Interface 143, L246 (1996).

${ }^{11}$ E. R. Lory, Solid State Technology (Nov.), 117 (1984).

${ }^{12}$ A. D. Hanser, C. A. Wolden, W. G. Perry, R. Therrien, and R. F. Davis (unpublished)

${ }^{13}$ M. D. Bremser, W. G. Perry, T. Zheleva, N. V. Edwards, O. H. Nam, N. Parikh, D. E. Aspnes, and R. F. Davis, MRS Internet J. Nitride Semicond. Res. 1, 8 (1996).

${ }^{14}$ R. J. Shul, R. D. Briggs, S. J. Pearton, C. B. Vartuli, C. R. Abernathy, J. W. Lee, C. Constantine, and C. Barratt, Mater. Res. Soc. Symp. Proc. 449, 969 (1996). 